\title{
EAST-WEST DIFFERENCES IN GENDER-ROLE ORIENTATION AND ENTREPRENEURIAL SELF- EFFICACY: A PROPOSED STUDY
}

\author{
Mary Conway Dato-on, Rollins College, USA \\ Stephen L. Mueller, Northern Kentucky University, USA
}

\begin{abstract}
Studies over the past decade suggest a persistent gap between men and women in their level of entrepreneurial activity (Minniti, Arenius and Langowitz 2005), in entrepreneurial orientation and propensity (Langowitz and Minniti 2007; Mueller 2004), as well as in the motivation, desire, and intention to become entrepreneurs (Minniti and Nardone 2007). Some researchers have attributed this "gender gap" to differences in how men and women perceive the environment for entrepreneurship and how they perceive their ability to succeed (Langowitz and Minniti 2007).

Gupta et al. (2009) examine the role of gender stereotypes in entrepreneurship and their differential influence on men's and women's entrepreneurial intentions. In a similar study, Mueller and Conway Dato-on (2008) test whether gender roleorientation (i.e. masculine, feminine, or androgynous) is a better predictor of entrepreneurial self-efficacy than biological sex. The results of both studies indicate that the intention to become an entrepreneur (as well as its antecedent of self-efficacy) is more likely determined by an individual's gender perception of self and values than by biological sex per se (Gupta et al. 2009: Mueller and Conway Dato-on 2008).

In addition to the influence of gender-role orientation on entrepreneurial self-efficacy, recent studies suggest national culture may also guide beliefs about one's ability to become a successful entrepreneur and actions toward becoming an entrepreneur (Baughn et al. 2006; Lee and Petersen 2000). The link between culture and entrepreneurship is based on the understanding that culture shapes the development of personality characteristics and prompts individuals in a society to engage in behaviors.

Despite this hypothesized link, a recent comparison study between respondents from the USA and Spain (Mueller and Conway Dato-on 20010) found no difference in ESE across the two cultures. While several possible explanations were offered for this outcome, the strongest conclusion was that more investigation was necessary across more culturally distant cultures with greater economic disparity as these two factors are said to influence entrepreneurial endeavors (Mueller and Goic 2003; Wennekers et al. 2005).

This abstract presents an ongoing study that is intended to extend the work of Gupta et al. (2009), Mueller and Conway Datoon $(2008,2010)$, and others by investigating the complex relationship between the multidimensional construct of genderroles and entrepreneurial self-efficacy across cultures through a preliminary study of respondents from South Korea. The eventual goal and plan for future research is to replicate the study in enough settings to enable cluster comparisons between different cultures.
\end{abstract}

References available upon request 